\title{
Azúcar amargo
}

El debate entre Dulbosal* y los cañeros-azucareros es una muestra de que también las distintas fracciones del capital tienen feroces contradicciones económicas. Tales contradicciones pueden ocurrir entre fracciones nacionales, nacionales y extranjeras, e inclusive, entre fracciones extranjeras pero que tienen intereses locales. De allí que la representación de la clase capitalista por un solo partido político puede funcionar muy bien de cara a otra u otras clases, pero no de cara a sí misma. Y la situación se complica todavía más cuando se está en el poder y adicionalmente la sociedad pasa por un proceso de cambio y transición, ya que entonces afloran más fácilmente los intereses encontrados de las distintas fracciones burguesas.

Ciertamente, no todos los cañeros son empresarios capitalistas, es sabido que entre tales productores se encuentran muchas cooperativas de la reforma agraria; sin embargo, el sector productor y beneficiador de la caña de azúcar está dominado por un segmento de la burguesía terrateniente salvadoreña y la burguesía agroindustrial, estos son los agremiados en Procaña y la firmante Agroindustria Azucarera de El Salvador, seguramente integrantes de los extintos FARO, de la Cruzada Pro Paz y Trabajo, del FAN y del ahora partido ARENA. Hacemos todas estas aclaraciones para que no se crea que actuamos ingenuamente y/o para evitar que se nos vaya a tildar de escritores a sueldo, como le ocurrió a H. Bruch, por intervenir en disputas donde media el interés pecuniario.

Aclarado lo anterior, debemos precisar que si bien es cierto que los capitalistas poseen muchos intereses comunes, también los tienen diferentes y cuando éstos se presentan, por mucho que se trate de ocultarlos bajo una y mil razones, bajo uno u olro discurso, siempre terminan mostrándose como lo que en realidad son: intereses fieros que superan los lazos políticos, ideológicos e, inclusive, los fuertes lazos de la sangre, aunque no les agrade reconocerlo.

En el caso que nos ocupa, tenemos por una parte a los productores de caña de azúcar y a los beneficiadores de la misma y, por otra parte, a los industriales confiteros y similares. Por facilidad de expresión identificaremos a los primeros con el nombre de "cañeros" y a los segundos, como "dulceros". La disputa entre ambos grupos está fundamentada en las ganancias, como lo reconocen los cañeros, pero con respecto a sus adversarios ya que, en su caso, su preocupación dicen que son las 380,000 personas que se verían afectadas por la quiebra del sector si el Gobierno accede a las pretensiones de los dulceros.

Pero, ¿qué es lo que está en disputa? Pues la aplicación de uno de los postulados neoliberales, cual es la apertura comercial. Para el caso concre-

* Gremial de fabricantes de dulces, chicles, chocolates, galletas y bocadillos de El Salvador. 
to: la libre importación de azúcar. Es muy probable, casi con seguridad podríamos afímarlo, que ambos grupos han estado a favor del modelo neoliberal y sin duda hasta votaron por ARENA y, al hacerlo, le concedían razón y sentido a las políticas de corte neoliberal propugnadas por la derecha; sin embargo, ahora los cañeros rechazan cualquier posibilidad de abrir el mercado a la competencia de otros azucareros del área.

Por tal razón es que han reaccionado de manera indignada y reclaman a los dulceros el no haber desarrollado su productividad, a fin de ser competitivos en el mercado internacional en vez de estar pidiendo importación de azúcar de menor precio. Igual razonamiento les podrían hacer los dulceros a los cañeros, ya que si éstos últimos hubiesen incrementado sus niveles de productividad, podrían perfectamente vender a menores precios el azúcar $y$, consecuentemente, no necesitarían mantener cautivo el mercado del endulzante, como parece que justicieramente reclaman los dulceros agrupados en Dulbosal.

Los dulceros manifiestan que se encuentran en grave situación de desventaja en relación con los precios del azúcar que paga su competencia en Guatemala y Honduras. Al no ser competitivos, obviamente producen menos y demandan menores cantidades de azúcar, lo que conduce a que se exporten mayores cantidades de azúcar nacional, la cual se vende en el exterior, aproximadamente, a 90 colones el quintal. Seguramente parte de esa azúcar barata regresa al país bajo la forma de dulces, chicles, galletas, etc., con los cuales es imposible competir.

Por tales razones es que solicitan al Gobierno que se les permita importar azúcar con un arancel preferencial del 5 por ciento, a fin de participar de manera competitiva frente a los dulceros del área. Con ello nos dicen que su problema no es de productividad, sino de costos de producción y que de comprar a buen precio el azúcar, estarían listos para participar con ventaja en la globalización que a otros preocupa, aflige e, inclusive, no les deja dormir tranquilos.

A tal petición de los dulceros, los cañeros responden desmintiendo muchas de las afirmaciones de los primeros y además aseguran que de permitirse la importación de azúcar, se estaría llevando a la quiebra a un sector compuesto por más de 380,000 personas que con su trabajo y esfuerzo contribuyen a la estabilidad social y económica del país.
Independientemente de que los desmentidos de los cañeros sean correctos o que muchas de sus afirmaciones no sean del todo verdaderas, aceptemos que de permitirse la cuasi libre importación de azúcar, este sector, que es uno de los pocos que aún se mantienen vivos en el agro, corre el riesgo de perecer.

¿Por qué hacemos tal afirmación? Porque si se permite a los dulceros importar azúcar para su consumo industrial, no existiría posibilidad de controlar qué parte de lo importado se destinará a otras actividades productivas, como la del pan de dulce, bebidas, reposterías, etc., o bien, para consumo directo. Además, ¿qué razón podría existir, racionalmente, para impedir que los comerciantes importaran azúcar para satisfacer las necesidades de consumo nacionales, si existiera la permisión para los industriales? Obviamente, ninguna.

Ahora bien, si tanto se cree en la doctrina neoliberal y se defiende tanto al mercado, ¿por qué en el caso del azúcar, no se busca sincerar los precios, como ha sido el caso en otros muchos productos incluyendo, por supuesto, el de la energía eléctrica? ¿Por qué los economistas defensores de la panacea neoliberal no pelean para que su nuevo Dios, el mercado, les haga justicia a los cañeros, dulceros y a todos los no diabéticos, felices consumidores de la dulzura maravillosa del azúcar de caña? ¿Será acaso que el mercado no es tan perfecto como se cree? ¿Será que las cualidades de omnisapiencia, justicia absoluta y visión perfecta que le atribuyen sus seguidores, son falsas? ¿Serán tan sólo argucias que han usado para rechazar todas aquellas medidas que no les convienen a los grupos que controlan el poder político, aunque sean de beneficio popular?

¿Por qué los discípulos de los "amigos de la libertad" apelan a la intervención protectora del Estado, abjurando de los sabios principios de sus maestros? Sería conveniente que los cañeros consultaran esta cuestión con su maestro De Sola y él, con su gran sabiduría, seguramente los convencerá de que opten por dejar que los precios del azúcar se sinceren. Al fin y al cabo, él no participa en esta actividad y, adicionalmente, la ocasión le es propicia para que demuestre sus dotes de estadista virtual.

Pero bien, si los cañeros venden la mayor proporción del azúcar en el exterior a un precio determinado por el mercado internacional, y al operar de esa manera pueden continuar produciendo $y$ 
hasta aumentar, año tras año, la producción, sin lugar a dudas es porque la actividad les resulta rentable y además actúan de manera consecuente con su visión ideológica de la economía. En consecuencia, si a nivel nacional nos imponen precios superiores a los internacionales será sólo por razones de voracidad financicra, sin importarles lucrar a costa nuestra, esto es, a costa de nosotros los consumidores nacionales de azúcar, ya sea por el gusto a lo dulce o a la ganancia que, no es menos dulce -eliminamos del nosotros a los pobres diabéticos que tienen que consumir sustancias endulzantes cancerígenas y que, adicionalmente, tampoco son dulceros para poder disfrutar de esa otra dulzura.

Los cañeros, con toda la prepotencia que les caracteriza, dirán que no es cierto que a ellos los mueva la ganancia, que su generosidad y patriotismo ya fueron puestos a prueba durante los negros años de la guerra, durante la reciente "agresión comunista" y que pese a las quemas de sus cañales - por traviesos gatos con trapos encendidos y amarrados a sus colas - muertes y secuestros de sus seres queridos, siempre estuvieron en el país generando riqueza, trayendo divisas mal pagadas en los años de Duarte y generando empleo para las empobrecidas e ignorantes turbas campesinas. Para agregar, a continuación, que ellos generan empleo con su actividad y que esto es una verdad que nadie, pero nadie les puede rebatir, inclusive, los dulceros.

Por nuestra parte deseamos señalar que cuando hemos cuestionado la visión económica neoliberal en la versión dogmática, fanática y torpe que manejan los economistas y políticos areneros, así como cuando hemos rechazado aceptar la globalización como algo ineludible y hasta nos hemos atrevido a proponer "una desconexión selectiva y temporal", ciertamente, no ha sido por razones político-ideológicas o por un simple afán de oponernos a los designios de los organismos internacionales, instrumentos del imperialismo. No, nos hemos opuesto porque cualquier doctrina, teoría o receta que no haya surgido en y para nuestra realidad es preciso tomarla con cierta precaución, cum granus salis, diría nuestro maestro $\mathrm{y}$, en consecuencia, luego de contrastarla con nuestra realidad

es muy posible encontrar una diversidad de excepciones que deben tomarse en cuenta.

El caso del azúcar vale como ejemplo maraviIloso, ya que su capacidad de rechazo a las posturas teóricas neoliberales es excelente, en razón de que resulta un total y absoluto contrasentido permitir la libre importación de azúcar, si al hacerlo se pone en peligro la producción nacional de la misma, con lo cual se perdería un uso rentable de la tierra y la generación de empleo y de divisas como resultado de la exportación de la misma.

Sin embargo, no es lícito que los cañeros nos impongan arbitrariamente precios que están por encima de los vigentes en el mercado internacional, lo cual los posibilita, seguramente, a obtener ganancias extraordinarias. De no ser así y habiéndose verificado su bajo nivel de rentabilidad, el gobierno podría establecer un mecanismo de subsidio temporal condicionado contractualmente para que los productores y beneficiadores eleven sus niveles de productividad, único mecanismo válido y efectivo para disminuir costos e incrementar los beneficios.

Debería quedar muy claro que para poder contar con el subsidio temporal, el incremento en la productividad no debería originarse en incrementos en la intensidad ni en la jornada de trabajo, ni mucho menos en contracciones o congelamiento de los salarios pagados a los trabajadores, ya que tales mecanismos no generan incrementos en la productividad.

Pues bien, aunque para algunos el azúcar está amarga, a otros nos ha permitido desarrollar algu- 
nos argumentos empíricos en contra del neoliberalismo y hacer uso de nuestra visión clasista de la sociedad para comprender esa esquiva realidad de la cual tantos gustamos hablar, no siempre para bien, por desgracia.

Aquiles Montoya 